\title{
Desarmar la frontera estereotipada desde el arte contextual de una colombiana en Quebec*
}

\author{
ALEXANDRE BEAUDOIN DUQUETTE**
}

\begin{abstract}
Disarming the Stereotyped Border from the Contextual ART OF A COLOMBIAN Woman In QueBec. This paper explores the possibilities of disarming the Canadian migratory propaganda from the perspective of Constanza Camelo Suárez, a Colombian visual artist living in the province of Quebec. To this effect, a counterpoint between two discourses is created (one from the State and the other from an artist), in which the incompatibilities between them are analyzed. This counterpoint is about two concepts: a stereotyped border (fixed, immobile and closed; an obstacle to knowledge) and a dissonant border (flexible, mobile and open; a necessary step towards knowledge).
\end{abstract}

Key words: mobilities, stereotypes, dissonance, diasporas, Canada, migration, multiculturalism

\begin{abstract}
Resumen
En este artículo se exploran las posibilidades de desarmar la propaganda migratoria canadiense desde la perspectiva de Constanza Camelo Suárez, una artista visual colombiana establecida en la provincia de Quebec. Para ello, se construye un contrapunto entre dos discursos (producidos uno desde el Estado y otro desde una artista), en el que se analizan las incompatibilidades entre los mismos. Dicho contrapunto gira en torno a dos conceptos: frontera estereotipada (fija, inmóvil y cerrada; un obstáculo al conocimiento) y frontera disonante (flexible, móvil y abierta; un paso necesario hacia el conocimiento).
\end{abstract}

Palabras clave: movilidades, estereotipos, disonancia, diásporas, Canadá, migración, multiculturalismo

\section{Introducción}

Dara Constanza Camelo Suárez, una artista colombiana establecida en la provincia de Quebec, la frontera - es un concepto primordial. Para afirmar que "la frontera, uno la lleva por dentro", se inspira en Guillermo Gómez Peña, un artista visual de origen mexicano radicado en Estados Unidos. ${ }^{1}$

Según Gómez Peña, el arte del performance ${ }^{2}$ es "un 'territorio' conceptual que tiene un clima y fronteras que fluctúan y un lugar en donde no solamente se toleran la contradicción, la ambigüedad y la paradoja, sino

* Artículo recibido el 31/05/17 y aceptado el 10/11/17.

** Universidad Nacional Autónoma de México (UnAm), Programa de Becas Posdoctorales en la unAm, becario del Instituto de Investigaciones Antropológicas, asesorado por la doctora Cristina Oehmichen Bazán. Universidad Nacional Autónoma de México, Instituto de Investigaciones Antropológicas, cubículo 116. Circuito Exterior, Ciudad Universitaria, Coyoacán, 04510, Ciudad de México <alexbeaudu@gmail.com>. orciD: http: / orcid.org/0000-0002-9624-0169.

1 Entrevista con Constanza Camelo Suárez, 2011.

2 El uso que hago de performance en el presente trabajo remite a la disciplina artística que también se conoce como "arte contextual" y no a la función performativa del lenguaje de Austin, lo cual implicaría un análisis de "actos de palabra" que no realizo en este texto, ya que exploro las posibilidades epistemológicas que ofrece el análisis de los documentos con base en la frontera disonante y la frontera estereotipada. El mismo Austin afirma que su teoría excluye las representaciones. 
que se fomentan" (2005: 22). ${ }^{3}$ En este caso, la frontera no se percibe como lo que Marc Augé llama un no lugar, es decir, "[u]n espacio en el que ni la identidad, ni la relación ni la historia estén simbolizadas", sino lo contrario, un "lugar de identidad [...], de relación [...] y de historia" (1998: 147).

El territorio del arte del performance es móvil, flexible e indefinido. Posee fronteras, pero éstas no son fijas y no producen lo que John Urry llama puntos de transferencias, es decir, unos "espacios de 'intermedialidad' [...] en donde las 'poblaciones' que son móviles pueden ser monitoreadas por varias agencias encargadas de vigilar el territorio e investigadas porque se encuentran temporalmente inmovilizadas" (Urry, 2007: 42).

Nos hallamos ante dos conceptos de frontera incompatibles: una inmóvil y fija; otra móvil y flexible. La primera se conforma como un instrumento que el Estado-nación usa para controlar a las poblaciones móviles. Es parte de lo que Glick Schiller y Salazar (2013) llaman un régimen de movilidad. La segunda corresponde a un terreno configurado como "un santuario temporal para otros artistas y teóricos rebeldes expulsados de sus campos monodisciplinarios y comunidades separatistas" (Gómez Peña, 2005: 23).

Esta doble cara del concepto de frontera puede constituir un punto de disonancia entre prácticas y discursos ejercidos desde una posición de poder y otros que no lo son. Para verificar esta hipótesis, propongo establecer una relación disonante entre una forma de expresión producida desde un Estado y una producida desde una artista.

En primer lugar, expongo cuatro conceptos: disonancia, propaganda, estereotipo y multiculturalismo. Luego, establezco un contrapunto entre una celebración del Canada Day y una acción artística, Dilatar o contraer el universo, ${ }^{5}$ así como algunos testimonios de su creadora, Constanza Camelo Suárez, artista visual colombiana establecida en Quebec. Esta obra la realizó en el año 2008 y yo no estaba presente en ese momento. Por lo tanto, mi análisis se basa en los testimonios de la artista y en los documentos que dejó en su sitio de internet. Aun así, refiriéndome al discurso de la artista, lo que se llevó a cabo sigue siendo un análisis de su acción y contribuye a que ésta perdure:
Michel de Montaigne afirmaba que la palabra pertenecía tanto a la persona que la dice como a la que la escucha. Mis acciones, nuestras acciones, se convirtieron en relatos que no sólo pertenecen a las personas que los narraron, sino también a las que quisieron escucharlos. [...] Mi arte reúne la intención y la difusión del resultado en un mismo proceso de creación [Camelo Suárez, 2015].

El presente trabajo tiene como objetivo explorar las posibilidades que ofrecen el discurso y la práctica de los artistas de las diásporas para desarmar los estereotipos de la propaganda de las instituciones migratorias canadienses.

En este sentido, constituye un esfuerzo para responder a lo que Homi K. Bhabha (2002: 18) describe como "la necesidad de pensar más allá de las narrativas de las subjetividades originarias e iniciales, y concentrarse en esos momentos o procesos que se producen en la articulación de las diferencias culturales". Por ello, exploro la posibilidad (sin tampoco considerarla como verdad absoluta) que plantea este intelectual cuando remite a Salman Rushdie para afirmar que "la visión más verídica puede pertenecer ahora a la doble visión del migrante" (Bhabha, 2002: 22). Asimismo, me inspiro en el trabajo de Geneviève Zarate que sostiene que el extranjero ocupa un lugar privilegiado para detectar los implícitos culturales. Según ella, el punto de vista del extranjero "induce la contingencia, la relatividad de todo sistema de valores establecido" y permite dar cuenta del "signo de una experiencia muda del mundo". Por lo mismo, constituye "el punto preciso en el cual puede producirse una ruptura epistemológica” (Zarate, 1986: 32).

El lugar del extranjero es propicio para la distancia etnográfica que Claude Lévi-Strauss describe como:

al asumir su papel, [el etnógrafo] buscó ya sea un modo práctico de conciliar su pertenencia a un grupo y la reserva que siente hacia éste, ya sea, simplemente, la manera de aprovechar un estado inicial de distanciamiento que le confiere una ventaja para acercarse a sociedades diferentes, de las cuales ya se encuentra a medio camino [1984: 459].

Al respecto, señala lo siguiente: "un enunciado performativo será particularmente hueco o vacío si está dicho por un actor en el escenario o si se encuentra insertado en un poema o hablado en un soliloquio. [...] Excluimos a todos éstos de nuestra consideración. Nuestros enunciados performativos, para bien o para mal, tienen que ser entendidos como emitidos en circunstancias ordinarias" (Austin, 1962: 22; traducción propia).

3 Todas las citas de fuentes escritas en inglés o francés fueron una traducción libre del idioma original.

4 Se puede ver el espectáculo del Canada Day en el siguiente enlace: https: / www.youtube.com/watch?v=4gAyOqrDOH8 [9 de noviembre de 2017].

5 El expediente visual de la obra puede consultarse en el siguiente enlace: http://constanzacamelosuarez.com/dossiervisuel/dilater-ou-contracter-lunivers / [9 de noviembre de 2017]. 
Dany Laferrière lo explica sencillamente aseverando que:

no por haber nacido en un país, uno lo conoce [...]. Uno lo siente más que cualquier otro, pero no lo conoce mejor porque le falta distancia. No lo ha estudiado. [Por lo tanto,] en esta obligación de observar atentamente al otro, uno a veces se descubre a sí mismo. Analizando así cada uno de sus gestos, uno tarda un tiempo antes de ver que se encontraba ante un espejo [2015: 56 y 77].

A diferencia del etnógrafo, quien tiene que ser "crítico a domicilio y conformista afuera" (Lévi-Strauss, 1984: 463), las diásporas no tienen que renunciar al menos a una cultura "para entregarse a todas" (Lévi-Strauss, 1984: 459). Lo anterior les concede una ventaja sobre el etnógrafo: pueden ser críticas en ambas situaciones, ya que éstas no son claramente definidas y a veces incluso se compenetran.

\section{La disonancia}

La dialéctica hegeliana plantea, de forma muy resumida, que el devenir surge del contacto entre el ser y el no ser. El autoconocimiento de una conciencia se produce cuando ésta choca con su propia negación. El conocimiento avanza con base en la contradicción entre un ente y algo que éste no es, es decir, el otro; del contacto y la tensión entre subjetividad y alteridad (Giner, 1982: 48 y Hegel, 2010: 73). Por ello, si la frontera entre estos dos polos se convierte en punto de encuentro y no una línea divisoria, ésta puede ser el lugar en donde empieza el aprendizaje.

La hipótesis de que el conocimiento avanza con base en contradicciones quizá pueda confirmarse de manera empírica gracias a los trabajos sobre disonancia cognitiva de Leon Festinger, así como sobre el acto de crear de Arthur Koestler. Esta demostración depende, en primer lugar, de que se acepte la premisa según la cual el conocimiento implica aprendizaje y, luego, que se asuma que la psicología del aprendizaje, como sostiene Rubén Ardila, se interesa en "un conjunto de fenómenos, o sea un campo específico de trabajo, en este caso los fenómenos relacionados con la modificación del comportamiento" (Ardila, 1979: 16). Así, el conocimiento implicaría aprendizaje, y éste, a su vez, una modificación del comportamiento.

¿Cómo se produciría esta modificación del comportamiento? Los resultados de los experimentos de Festinger nos enseñan que, cuando nos encontramos frente a elementos de información incompatibles, tendemos a cambiar nuestro comportamiento, con el afán de generar coherencia. Este fenómeno se conoce como disonancia cognitiva (Festinger, 1962: 95):

si una persona conoce varias cosas que no son coherentes las unas con las otras, encontrará una manera para que éstas se vuelvan más coherentes. Se dice que dos elementos de información que no concuerdan psicológicamente se encuentran en una relación disonante el uno con el otro. [...] Al igual que el hambre lleva a una persona a comer, lo mismo ocurre con la disonancia, la cual lleva a una persona a cambiar sus opiniones o comportamiento [Festinger, 1962: 95].

Si la disonancia cognitiva nos conduce a modificar nuestro comportamiento, sería lógico contemplarla como una posibilidad pedagógica ${ }^{6}$ y de construcción de conocimiento. Lo anterior concordaría con las conclusiones de Arthur Koestler en The Act of Creation: en el humor, el arte y las ciencias entra en juego un pensamiento bisociativo:

el pensamiento que queda confinado a una sola matriz [...] consiste en el ejercicio de una habilidad más o menos flexible, éste permite llevar a cabo únicamente un tipo de tareas que ya se ha ejecutado en el pasado; este tipo de pensamiento es incapaz de alcanzar logros originales y creativos [Koestler, 1964: 44].

6 Aquí, uso la palabra "pedagógica" en la acepción que Noam Chomsky llama "tradicional”: "que sostiene que el objetivo más alto en la vida es investigar y crear, buscar la riqueza del pasado, tratar de interiorizar aquello que es significativo para uno, continuar la búsqueda para comprender más a nuestra manera” (Chomsky, 2012: s. p.) o incluso desde una concepción más radical como la de Freire, para quien la pedagogía debe hacer "de la opresión y sus causas el objeto de reflexión de los oprimidos, de lo que resultará el compromiso necesario para su lucha por la liberación, en la cual esta pedagogía se hará y se rehará" (Freire, 2005: 42). No me refiero a lo que Homi K. Bhabha describe como la "temporalidad continuista y acumulativa" de la "producción de la nación como narración" (2002: 182). Desde mi punto de vista, lo anterior corresponde a un proceso de adoctrinamiento. Prefiero no asignar el término "pedagogía" a este significado porque, al confundir "adoctrinamiento" con "pedagogía", terminaría legitimando la desublimación de un término por parte de las instancias de poder para ocultar objetivos estratégicos de dominación, un poco como cuando se nombra "Departamento de Defensa" a una entidad que se dedica a atacar más que a defender (véase Baillargeon, 2006: 27) o cuando se denomina como "sistema de educación" a lo que la Comisión Trilateral llama un "sistema de adoctrinamiento de la juventud" (Crozier, Huntington y Watanuki, 1975: 162). Es decir, se emplea la connotación positiva de una determinada palabra para remplazar a otra que tiene una negativa. Un ejemplo clásico de lo anterior es el uso de la connotación positiva que adquirió la palabra "público" en el siglo xix para sustituir la palabra "propaganda" por "relaciones públicas" (Curtis, 2002; Habermas, 1997). 

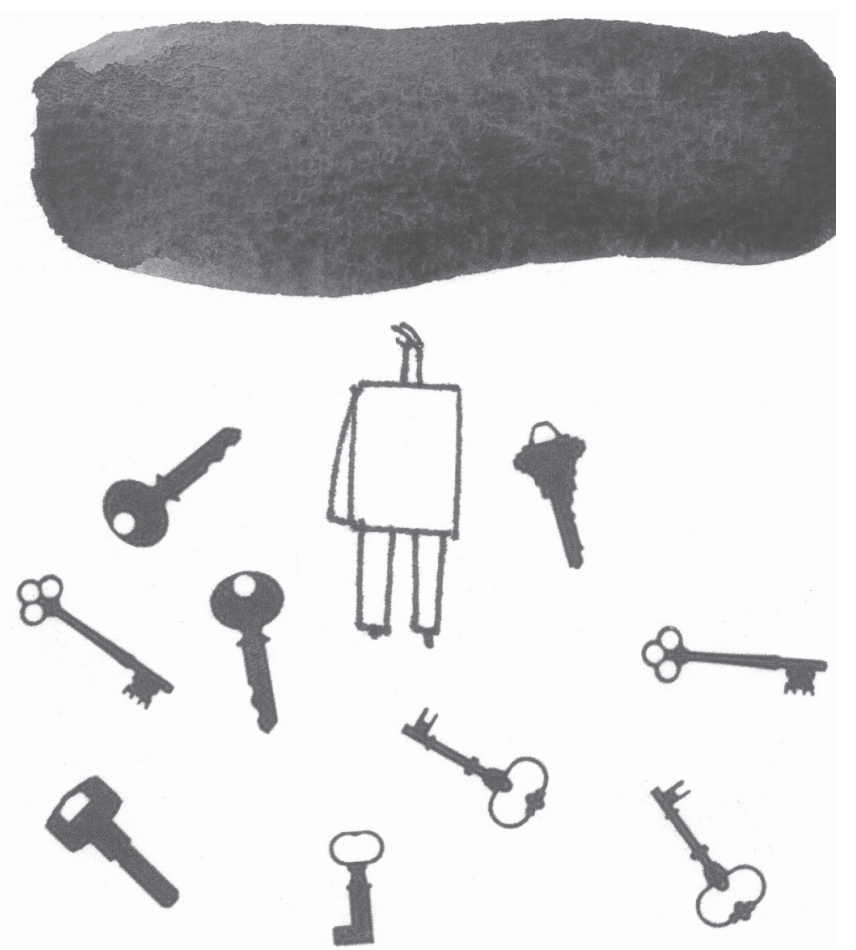

El pensamiento no debe de limitarse a una sola matriz para generar creatividad, aprendizaje y conocimiento, sino superar lo asociativo y volverse bisociativo:

Cuando dos matrices de percepción o raciocinio independientes interactúan, el resultado [...] puede ser una colisión que termina en una risa, una fusión en una nueva síntesis intelectual o una confrontación dentro de una experiencia estética [Koestler, 1964: 45].

La primera situación remite al ámbito del humor; la segunda, a la ciencia y la última, al arte. La segunda situación me interesa particularmente en este caso, aunque tanto el ámbito del humor como el de la ciencia y del arte comparten más aspectos en común de lo que sus respectivas tradiciones e instituciones suelen estar dispuestas a reconocer.

Si bien Koestler no menciona a Festinger, su definición del pensamiento bisociativo comparte rasgos con la disonancia cognitiva; remiten a estados psicológicos en los que coexisten pensamientos incompatibles, de los cuales emerge alguna novedad: un cambio de comportamiento, una risa, un descubrimiento o una experiencia estética. Así, el conocimiento y el aprendizaje cobrarían forma en la frontera entre nuestra subjetividad $\mathrm{y}$ lo que nos es ajeno $\mathrm{u}$, obviamente, desconocido.

Festinger afirma que dicho estado psicológico puede compararse a lo que siente el cuerpo cuando pasa hambre. Por lo tanto, se trata de una sensación intensa: es nuestra concepción del mundo que se desmorona.
Es legítimo entonces que el individuo que la enfrenta acuda a algún mecanismo de defensa. Uno de éstos son los estereotipos.

\section{Estereotipos y propaganda}

En 1922, Walter Lippmann compartió en su obra Public Opinion un hallazgo de alto impacto: "Dentro de la cacofonía de este nuevo mundo feliz, 'el chillido, el estruendo y el color' de los medios de comunicación modernos dejaban una huella notoria en el imaginario popular" (Ewen y Ewen, 2006: 7). A esta huella, Lippmann la llamó estereotipo.

La palabra tiende hoy en día a convertirse en un lugar común y a confundirse con prejuicio o arquetipo. Homi K. Bhabha llega incluso a concebir los estereotipos como "un modo de representar la otredad" (2002: 93), cuando la construcción de una imagen del otro no sólo implica la construcción de una imagen de lo propio, sino de "una imagen del mundo". Por ello es importante regresar a la definición de Lippmann, quien dio a la palabra el significado que opera en la historia.

Margaret L. Andersen establece una relación disonante entre los estereotipos y el conocimiento: éstos se basan en "falsos juicios, conocimientos incorrectos e inexactos sobre los otros -en otras palabras, en falsos conocimientos". Para retarlos, uno tiene que "basarse en el conocimiento" (Andersen, 2006: 74). Si aceptamos lo anterior, concordaríamos con Maddalena De Carlo: los estereotipos y los prejuicios que éstos engendran constituyen "un obstáculo al conocimiento de la verdad", pues no tienen en cuenta los datos objetivos (1997: 281). Corresponderían a una frontera fija que se erigiría como un muro entre nosotros y el conocimiento de la realidad; producirían lo que Lippmann (2003) llama un pseudoentorno.

Antes de adquirir su significado moderno, la palabra estereotipo remitía al ámbito de la imprenta; designaba un molde que permitía la "reproducción masiva de material impreso" (Ewen y Ewen, 2006: 4). El prefijo estereo viene del antiguo griego stereos, lo cual significa "sólido, duro o fijo" (Ewen y Ewen, 2006: 4). Etimológicamente, el significado de la palabra acuñada por Lippmann se deduce como una imagen fija del mundo que se reproduce de forma masiva. Por lo tanto, no es de sorprender que el concepto de Lippmann nazca en un contexto en el que afloraba la industria de las "relaciones públicas" o, como se le llamaba en sus inicios, la propaganda.

Al definir el concepto, Lippmann intentaba explicar, desde una postura poco democrática, cómo las personas comunes y corrientes usaban inconscientemente 
imágenes mentales heredadas de su cultura, con el afán de dar sentido a una existencia absurda en un mundo caótico, inabarcable y disonante:

Los estereotipos constituyen una imagen ordenada y más o menos coherente del mundo, a la que nuestros hábitos, gustos, capacidades, consuelos y esperanzas se han adaptado por sí mismos. Puede que no formen una imagen completa, pero son la imagen de un mundo posible al que nos hemos adaptado. En él, las personas y las cosas ocupan un lugar inequívoco y su comportamiento responde a lo que esperamos de ellos. Por otro lado, hace que nos sintamos como en casa, porque pertenecemos a él, somos miembros de pleno derecho y en su interior sabemos cómo y por dónde movernos. En ese mundo encontramos, además, el encanto de lo que nos resulta familiar, normal y fiable, y sus vericuetos y contornos siempre están donde esperamos encontrarlos. Por mucho que hayamos renunciado a grandes tentaciones para caber en el molde, una vez dentro sentiremos que se ajusta a nosotros de forma tan acogedora como nuestro par de zapatos más usados [Lippmann, 2003: 93].

Se trata entonces de una imagen simple del mundo y de nuestra existencia. Su simplicidad estriba en que nos lleva a creer que todo en este mundo, particularmente nosotros, ocupa un lugar conocido y responde a nuestras expectativas. Asimismo, esta imagen del mundo es ficticia, pues es construida por el individuo gracias a los referentes que le brinda su cultura, los cuales sirven para elaborar un relato que da sentido a su existencia.

De este modo, los estereotipos nos ofrecen la ilusión de que la realidad en la que nos encontramos es coherente, abarcable y tiene sentido, que ésta no es ni absurda ni caótica; no es ni hostil ni disonante. En suma, los estereotipos nos proyectan una imagen del mundo tal como creemos que es, tal como deseamos que sea y tal como tememos que sea. Se incrustan en nuestro inconsciente, por lo que "su impronta radica en que precede al uso de la razón” (Lippmann, 2003: 95).

Desarmar los estereotipos significa entonces desnudar "el lenguaje del poder" (Ewen y Ewen, 2006: 487) y dejarlo sin palabra. Herbert Marcuse describe el carácter autoritario de este lenguaje afirmando:

Todas [sus frases] tienen en común un alejamiento y contracción de la sintaxis que limita el desarrollo del significado, creando imágenes fijas que se imponen a sí mismas con su abrumadora y petrificada concreción. Es la conocida técnica de la industria de la publicidad, donde se le emplea metódicamente para "establecer una imagen" que se fija en la mente y en el producto, y sirve para vender los hombres y los bienes. [...] Se espera que el lector o el oyente asocie (y lo hace) con ellos una estructura fija de instituciones, actitudes, aspiraciones, y se espera que reaccione de una manera fija y específica [Marcuse, 1993: 121].

Retar los estereotipos, como propone Andersen, es una tarea complicada porque "no hay nada tan impermeable a la educación o a la crítica como los estereotipos, ya que se acuñan a sí mismos sobre las pruebas en el preciso momento de obtenerlas" (Lippmann, 2003: 95). Es también una operación delicada, porque, por una parte, son "la garantía de nuestro amor propio y la proyección al mundo del sentido que cada uno de nosotros tenemos de nuestra valía personal, nuestra posición y nuestros derechos" (Lippmann, 2003: 94). Por otra, "cualquier alteración de nuestros estereotipos nos [parece] un ataque contra los mismísimos pilares del universo" (Lippmann, 2003: 93).

Cuando cae la visión estereotipada que uno tiene del mundo, emerge la disonancia cognitiva. Uno se halla ante elementos de información incompatibles: choca la representación ficticia del mundo con el mundo empírico o, retomando a Lippmann, el "pseudoentorno" con el "entorno real". En este sentido, al constituirse como un acercamiento indirecto con otras formas de ver el mundo, quizá el arte pueda desarmar nuestros estereotipos, amortiguando el vértigo que sentimos cuando éstos se derrumban.

Según Lippmann, los individuos piensan de manera estereotipada. Ello justificaría la existencia de las relaciones públicas, porque significaría que no tendrían las competencias para participar en la toma de decisiones políticas. Lippmann y sus correligionarios, como Edward L. Bernays, consideraban que la sociedad tenía que ser gobernada por un pequeño grupo de expertos, a quienes se les otorgaría el privilegio de protegernos de nosotros mismos y de la posibilidad de que caigamos en el caos:

Nos gobiernan merced a sus cualidades innatas para el liderazgo, su capacidad de suministrar las ideas precisas y su posición de privilegio en la estructura social. Poco importa qué opinión nos merezca este estado de cosas, constituye un hecho indiscutible que casi todos los actos de nuestras vidas cotidianas [...] se ven dominados por un número relativamente exiguo de personas $[\ldots]$ que comprende los procesos mentales y los patrones sociales de las masas.

[...]

No solemos ser conscientes de lo necesarios que son estos gobernantes invisibles para el buen funcionamiento de nuestra vida en grupo [Bernays, 2008: 15-16]. 
De tal suerte, las relaciones públicas jugarían un papel preponderante en los Estados considerados como democráticos, en donde no se puede, en teoría, acudir tan fácilmente a la represión violenta. En palabras de Noam Chomsky (2002: 11), "la propaganda es a la democracia lo que la cachiporra al Estado totalitario", y en las de Bernays (2008: 28), "es el brazo ejecutor del gobierno invisible".

Los estereotipos constituyen la materia prima de la propaganda. Edward Bernays, el inventor de este arte, sintetiza la relación entre propagandista y estereotipos señalando: "El consejero en relaciones públicas a veces usa los estereotipos corrientes, a veces los combate y a veces crea unos nuevos" (1961: 162).

De acuerdo con Lippmann, la censura es indispensable para que se construya propaganda:

Si no se establece algún tipo de censura, la propaganda en el sentido estricto del término resulta imposible. Por consiguiente, es necesario que exista alguna barrera entre el público y los sucesos. El acceso al entorno real debe ser limitado antes de que alguien pueda crear un pseudoentorno que le parezca razonable o deseable [2003: 52].

Así, el conocimiento estereotipado del mundo que produce la propaganda o relaciones públicas nace en la frontera entre nosotros y los hechos, en una
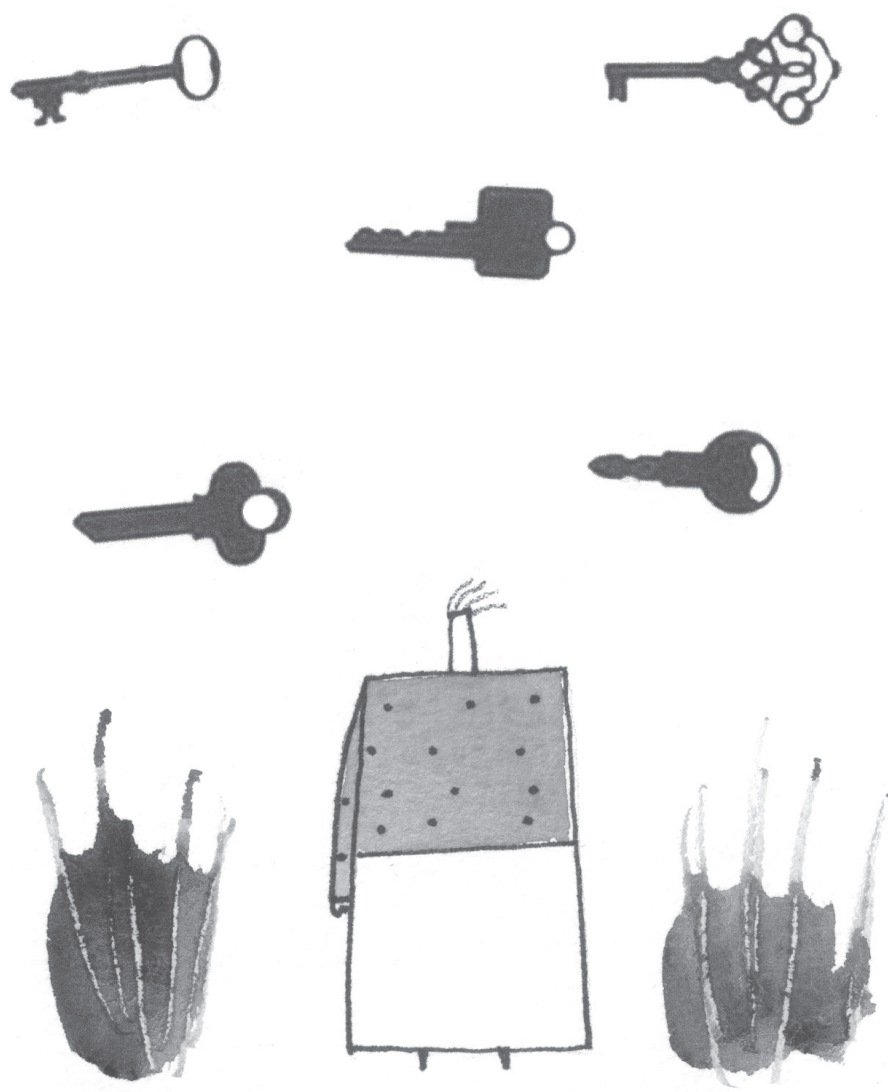

frontera fija que nos impide entrar en contacto con la alteridad, al proyectarla de manera ficticia como algo ya conocido y simple.

Si esta frontera se derrumba, entramos en un estado de disonancia cognitiva: nos percatamos de que vivimos en una realidad que no corresponde a la imagen que teníamos de ésta. Ello nos obliga a cambiar nuestro comportamiento a fin de generar coherencia. Podemos entonces adaptar nuestro mundo estereotipado para "reparar" o reconstruir el muro que habíamos edificado entre nosotros y los hechos. También podemos considerarlo una oportunidad de aprendizaje.

Guizá el arte pueda cumplir una función en este último escenario, al convertirse en una frontera móvil, abierta y flexible entre nosotros y el entorno real. Se amortiguaría así la disonancia cognitiva; se le abordaría de forma indirecta.

\section{El multiculturalismo canadiense}

El multiculturalismo orienta el discurso de las instituciones gubernamentales canadienses. Éste suele confundirse con un estado de hecho, el de la diversidad cultural, y tiende a ser empleado como su antonomasia. De este modo, la crítica al multiculturalismo suele confundirse con una crítica a la diversidad cultural.

Entonces, el multiculturalismo se proyecta como el modelo más incluyente de "gestión" de la diversidad cultural. Neil Bissoondath observa que el multiculturalismo, a pesar de fomentar una percepción estereotipada y simplificada de las culturas, se ha convertido en un culto:

Reconocimiento, apreciación, comprensión; sensible, receptivo, respetuoso; promueve, fomenta, preserva: estas palabras y otras como éstas se enuncian una y otra vez en la Ley del Multiculturalismo [canadiense], repetidas en medio de un matorral de fraseo legal como los mantras de buena voluntad y fraternidad empleados por los cultos religiosos [Bissoondath, 1994: 41].

De ello resulta que "uno se siente un poco ingrato en admitir que estas palabras le evocan menos un suspiro de seguridad que un escalofrío de suspicacia" (Bissoondath, 1994: 42). Ésta no es infundada, pues el multiculturalismo emergió como un concepto vacío que se fue llenando de significado en la historia reciente de Canadá, de acuerdo con los intereses de las administraciones en turno. Esta política se convirtió, por una parte, en un barniz humanitario aplicado al uso de la diversidad cultural por parte del Estado canadiense como una ventaja competitiva en un mercado 
globalizado. Por otra, se constituyó en un discurso que legitima políticas migratorias excluyentes basadas en el argumento de la necesidad de resguardar la seguridad de un país que se proclama como un modelo de administración de la diversidad cultural. ${ }^{7}$

Pese a ello, no se suele criticar al multiculturalismo canadiense por considerarlo excluyente, sino por lo contrario. Por ejemplo, Gérard Bouchard afirma que éste "no toma en cuenta el contexto y el porvenir de la cultura mayoritaria" (2011: 398), refiriéndose a la condición particular de los canadienses de habla francesa en Quebec, en donde éstos forman una cultura mayoritaria, a la vez que constituyen una cultura minoritaria en el contexto norteamericano. ${ }^{8}$

Esta crítica al multiculturalismo infiere que éste tiene en cuenta los intereses de las minorías que no "forman una cultura mayoritaria", proyectando así a Canadá como un modelo insuperable de empatía hacia los inmigrantes y las diásporas, como si este modelo de administración de la diversidad cultural fuera diseñado desde y en función de sus intereses, de ahí la pertinencia de rescatar otras perspectivas sobre el tema.

\section{María Aragón y el Canada Day}

Entre 2007 y 2014, se podían consultar 38 "historias de éxito" en el sitio de internet del Ministerio de Ciudadanía e Inmigración canadiense. Una de éstas contaba cómo María Aragón, una niña canadiense hija de inmigrantes filipinos, alcanzó la gloria luego de que Lady Gaga redirigiera a los millones de seguidores de su cuenta de Twitter a un video en el que la pequeña mostraba sus talentos como cantante. Luego, el entonces primer ministro de Canadá, Stephen Harper, la invitó a cantar con él durante su campaña electoral. ${ }^{9}$
María Aragón fue también convocada a entonar el himno nacional durante las celebraciones del Canada Day en Ottawa, en presencia de las más altas autoridades del país, incluyendo el duque y la duquesa de Cambridge, los príncipes de la monarquía británica. ${ }^{10}$ En la página de internet en la que aparecía la historia, se facilitaba un enlace hacia un video de la ceremonia en la que la niña interpretó el himno nacional canadiense. Esta representación nos muestra algunas fronteras que el discurso del multiculturalismo produce. Éstas sobresalen aún más cuando se contrapone este documento al trabajo de Constanza Camelo Suárez.

De este video se desprende la imagen de Canadá como un país armonioso, cuyas autoridades están en simbiosis con la población, como si no existieran fronteras entre las unas y la otra. Al igual que en un mundo estereotipado, "las personas y las cosas ocupan un lugar inequívoco y su comportamiento responde a lo que esperamos de ellos" (Lippmann, 2003: 93). María canta el himno en los dos idiomas oficiales, dando así la impresión de una nación unida en la diversidad.

Empero, la preocupación por la seguridad nacional, legitimada por el discurso del multiculturalismo en aras de su propia protección, separa a las autoridades de la población en una frontera marcada por la omnipresencia de la policía y del ejército, la cual, paradójicamente, intimida y divierte a la vez. El espectáculo aéreo de las Fuerzas Aéreas y el traje folclórico de la policía montada, quienes saludan solemnemente mientras se entona el himno nacional, entretienen e impresionan. A pesar de eso, un mensaje implícito queda claro para todos. David Graeber (2015: 188) lo formula así: "cruzas esta línea y te disparo" o, por lo menos, te arresto.

Estamos ante una frontera cerrada, fija, inmóvil, impuesta desde una posición de poder y que se camufla detrás del barniz de los símbolos nacionales como la

7 Para una contextualización crítica del multiculturalismo canadiense basada en los argumentos de Liette Gilbert y de Neil Bissoondath en la que reviso esta política, la propaganda y la construcción de estereotipos, véase Beaudoin Duquette (2016).

8 Sometí para publicación en la revista De raíz diversa un artículo en el que propongo una crítica al interculturalismo quebequense, esta vez, desde la obra de Dany Laferrière. En ese texto se ofrece más información sobre este "modelo de gestión de la diversidad cultural" y la situación particular de la provincia de Quebec. El artículo se encuentra en dictamen.

9 Para una versión traducida de la "historia de éxito", véase Beaudoin Duquette (2015: 238-239).

${ }^{10}$ Resultaría interesante establecer un paralelo con la conversación entre Judith Butler y Gayatri Chakravorty Spivak publicada con el título ¿Quién le canta al Estado-nación? (2009), cuyo punto de partida es la traducción del himno nacional estadounidense al español, su uso por parte de movimientos sociales en las protestas en contra de reformas migratorias de 2006 y la reacción del entonces presidente George W. Bush en contra de que se cantara el himno nacional en otro idioma que no fuera el inglés. Sin embargo, ambas manifestaciones sólo tienen en común que proyectan a inmigrantes que cantan un himno nacional. Por lo demás, en el caso de ¿Quién le canta al Estado-nación? se trata de actores de la sociedad civil que usan el himno en otro idioma que el inglés como forma de protesta y que incluso suscitan un rechazo por parte del presidente. En el otro caso, si bien se trata de una inmigrante que entona el himno, ella lo hace en los dos idiomas oficiales (no en su lengua materna), en el marco de un evento oficial y con el beneplácito de las más altas autoridades del país. No obstante, un contrapunto entre esas dos manifestaciones podría inspirar a quienes se interesan en lo performativo en la política, lo cual no responde al objetivo del presente trabajo. 
monarquía, el primer ministro, el gobierno, el Parlamento, las banderas, los colores patrios, la policía montada y la recientemente cooptada diversidad cultural. Así, se van dibujando las fronteras estereotipadas desde el Estado canadiense, escondiéndose debajo de una comunión nacional, y me hacen recordar tanto a 1984 como a Un mundofeliz; una síntesis del Gran Hermano y del soma.

Roberto DaMatta denomina a este tipo de actos como acontecimiento extraordinario previsto. Empero, a diferencia del caso brasileño estudiado por el sociólogo, el Estado canadiense logra juntar de manera simultánea "lo altamente ordenado" y "los sucesos dominados por la brincadeira, diversión o licencia" (DaMatta, 1997: 57) en lo que DaMatta describe como "un ritual diurno, claro, donde los espacios están bien marcados" (1997: 65).

De ello, resulta una confusión en cuanto a saber si los aplausos de la multitud van dirigidos a las autoridades o a María Aragón: la cantante es cooptada por la autoridad y colocada en la fachada de la frontera entre las autoridades y la población. De paso, las autoridades cosechan los aplausos y tendemos a olvidar que la administración de Stephen Harper no simpatizó mucho con la idea de fomentar la inmigración y la emancipación de la diversidad cultural en Canadá. En efecto, cualquiera que haya puesto una pizca de atención a la última campaña electoral federal se habrá fijado en que el Partido Conservador le apostó a estigmatizar a los musulmanes con fines electoralistas. Se genera la impresión de que la frontera entre el Partido Conservador, su candidato y las minorías se ha borrado.

$\mathrm{El}$ concepto de dispositivo ritual extendido se aplica en buena medida a la situación. Ocurre lo que Marc Augé describe como "las apariciones públicas de figuras políticas", en donde se "trata una alteridad (la del público en general [...])" y se "intenta establecer, por obra de una identidad nacional reafirmada desde el comienzo [...], un 'consenso' o una mayoría...” (1998: 96). Esta frontera entre dicha figura política (encarnada en los altos funcionarios canadienses y los representantes de la monarquía británica) y la alteridad se oculta debajo del barniz de los símbolos nacionales.

Con todo, la construcción del dispositivo ritual extendido en Canadá implica una diferencia con el caso francés que describe Augé: la creación de un nacionalismo canadiense es un proceso reciente y el multiculturalismo constituye un elemento central de esta construcción. Por lo tanto, es incómodo acudir a "continuas referencias al pasado" porque, antes de los años sesenta, las políticas canadienses de inmigración y de administración de la diversidad cultural eran abiertamente racistas y las diásporas asiáticas fueron particularmente afectadas por las mismas (véase Beaudoin Duquette, 2015: 84-100).

Más que acudir al pasado, se trata de borrarlo y ensalzar la ficción de un presente utópico encarnado en el multiculturalismo. El Estado canadiense plantea lo que Homi K. Bhabha (2002: 197) describe como “'la obligación de olvidar' u olvidar recordar". Tanto la "construcción del futuro y la continua referencia al pasado" se sintetizan en un eterno presente ficticio, el cual sí tendría un "carácter grandioso de una evocación mítica” (Augé, 1998: 98-99); un presente ficticio estereotipado con fronteras fijas.

\section{Dilatar o contraer el universo versus la "historia de éxito"}

Un día de 2008, en la céntrica estación de metro BerriUQAM en Montreal, en la provincia de Quebec, un grupo de migrantes caminan con los ojos vendados por el pasaporte de su país de origen. Van acompañados por perros guías prestados por la fundación Mira, una organización sin afán de lucro que entrena a los animales para "aumentar la autonomía y la inclusión social de las personas discapacitadas". ${ }^{11}$ De la cintura de quienes protagonizan la acción, cuelgan unos aparatos electrónicos, de los que emanan de forma aleatoria el himno nacional de Canadá y el del país de origen del actor. Cuando los actores se acercan unos a otros, se produce una cacofonía.

En 2011 , Constanza Camelo Suárez me explicó que creó su intervención en colaboración con el Studio $\mathrm{XX}$, un centro de artistas feminista de Montreal. Su proyecto involucraba a 15 migrantes. Algunos eran amigos cercanos y los demás eran personas que conoció en centros de acogida para inmigrantes, de diversos sectores de la ciudad:

Les conté cuál era la propuesta y así la gente se fue uniendo al proyecto. La idea es que, cuando otras personas se unen a la acción, no lo hagan por relación económica -es decir, no le pago a nadie cuando viene y trabaja conmigo-, tampoco quiero que haya una relación de fuerza. Realmente, lo que nos reúne es el interés, lo que está entre nosotros, lo que compartimos. Me parece muy importante lo que nos hace estar juntos. ${ }^{12}$

\footnotetext{
${ }^{11}$ Fondation Mira <http: / /www.mira.ca/fr/qui-sommes-nous-/3/mission_43.html> [6 de noviembre de 2017].

12 Entrevista con Constanza Camelo Suárez, 2011.
} 
La artista cuenta que los datos del himno nacional de los países de origen de los actores y el de Canadá se mezclaban en un microcontrolador al ritmo de sus pasos y "producían ruido o una imagen clara del sonido del himno o los dos himnos que se superponían [...] hasta crear cacofonías". Cuando los actores se encontraban cerca los unos de los otros, se podía, por ejemplo, "escuchar el himno de Argentina con el de Colombia que se mezclaban con el canadiense". ${ }^{13}$

En el espacio de un momento, esta comunidad de acción devuelve la esencia pública a la estación de metro, un espacio que tiende a convertirse a menudo en un no lugar. Las fronteras habituales entre los individuos se difuminan; dejan de ser fijas y se vuelven disonantes. Constanza Camelo Suárez y sus actores se apropian de un "lugar de paso", un "espacio anónimo" (Augé, 1998: 99) y, de manera efímera, dotan este no lugar de nuevos sentidos.

Cuando la artista incorpora los símbolos nacionales a su acción, el pasaporte enceguece; el sonido del himno nacional genera disonancia y se erige como un obstáculo para la comunicación, ensordece. La presencia de los perros guías llama la atención sobre la metáfora de la discapacidad, pero también acerca de la posibilidad de ser ayudado o de ayudar. En la cotidianidad de los transeúntes del metro de Montreal, los símbolos nacionales pierden su poder de barnizar las fronteras creadas por el Estado-nación. Se devela y señala la frontera estereotipada que divide y entorpece el diálogo entre las diferencias.

La artista sostiene que "lo multicultural", detrás de su afirmación como reconocimiento de que "cada cultura tiene su derecho en un lugar dado", le resulta problemático: este concepto "guetoíza aún más a las culturas y no permite que éstas vengan a intercambiar", que puedan compartir lo que traen y recibir lo que se les da. ${ }^{14}$

Ella construye una dialéctica en la que su obra propone, en un primer tiempo, los símbolos nacionales con los que ocupa el espacio público y que lo vienen a perturbar. En segundo lugar, se encuentran los transeúntes que son, en esta situación precisa, ajenos a estos símbolos. En tal contexto, los símbolos nacionales no logran ser instrumentalizados, porque en este no lugar o punto de transferencia, como lo llamaría John Urry, dichos símbolos constituyen un obstáculo que los distrae en su recorrido. La utopía multiculturalista que rayaba en lo huxleyano durante el Canada Day aparece ahora como una distopía orwelliana.
Constanza Camelo Suárez se inspira en el trabajo de Guillermo Gómez Peña para proponer formas alternativas de convivencia que no se enmarcarían ni en el multiculturalismo ni en el interculturalismo. Éstas funcionarían "como un ruido", el cual "no es claro, precisamente porque, de puro, no queda nada". Los sonidos que cargan los actores, en un principio, ensordecen y entorpecen la comunicación. A medida que se combinan y alternan, estos sonidos ya no se parecen a los himnos nacionales. Así es como los encuentros entre los actores dan luz a algo nuevo, a un ruido "que nos identifica singularmente y que, por momentos, [es] algo muy claro, pero, en otros, es una cosa matizada"; que, a veces, "es totalmente cacofónico y así varía [...] en relación con quien yo me encuentro". ${ }^{15}$

$\mathrm{Al}$ exacerbar la frontera estereotipada producida por los símbolos nacionales, la intervención hace emerger una frontera disonante. Ésta constituye una etapa hacia el otro; cruzarla depende de nuestra voluntad. No es fija. Significa el reconocimiento de una subjetividad propia y de una alteridad. Es disonante porque nos expone a elementos potencialmente incompatibles con la representación que nos hacemos del mundo.

Puede ser entendida como un punto de fricción, considerado por Anna Lowenhaupt Tsing como "las calidades incómodas, desiguales, inestables y creativas de las interconexiones que surgen mediante la diferencia" (2005: 4). En efecto, un vehículo avanza cuando:

[u]na rueda gira por su encuentro con la superficie de la carretera; si gira en el aire, no nos lleva a ningún lado. $\mathrm{Al}$ frotar dos palos el uno contra el otro, se producen calor y luz; un solo palo sólo es un palo. En tanto imagen metafórica, la fricción nos recuerda que los encuentros heterogéneos y desiguales nos pueden llevar a nuevas configuraciones de cultura y de poder [Lowenhaupt Tsing, 2005: 5].

Esta frontera significa la posibilidad de que emerja un nuevo conocimiento a partir del encuentro entre dos entes diferentes mediante un proceso dialéctico. Siguiendo la teoría de Koestler, ofrece un contexto propicio para el pensamiento bisociativo, en el que formas de pensar aparentemente incompatibles se encuentran para crear algo nuevo.

La frontera disonante cumple una función como la que describe Marc Augé (2007: 21): "no es una

13 Entrevista con Constanza Camelo Suárez, 2011.
14 Entrevista con Constanza Camelo Suárez, 2011.
15 Entrevista con Constanza Camelo Suárez, 2011. 
barrera, sino un paso, ya que señala, al mismo tiempo, la presencia del otroy la posibilidad de reunirse con él". Es la línea de disonancia cognitiva que separa dos conjuntos de elementos de información o dos matrices de pensamiento aparentemente incompatibles, una subjetividad y una alteridad. Dos subjetividades, que son, el uno para el otro, dos alteridades, pueden cruzarla para crear una posibilidad de aprendizaje.

Por esta razón, Constanza Camelo Suárez está en busca de "accidentes" o "insolencias situacionales", un concepto inspirado en el de situational improprieties de Erving Goffman. Éstas ocurren cuando "un individuo, de manera intencional o no, se comporta de una forma considerada como inadecuada para los demás” (Goffman, 1966: 217). Camelo Suárez explica que los accidentes situacionales, que se suelen atribuir a individuos socialmente disfuncionales, permiten tomar una distancia con respecto a "las reglas de comportamiento social habitual, normal, normativizado".

La insolencia situacional es, según Camelo Suárez, "totalmente personal y [...] totalmente ligad[a al] inconsciente". Ella remite a Goffman para afirmar que se trata de "un momento clave al que deberíamos prestar más atención para que nuestras sociedades no lleguen

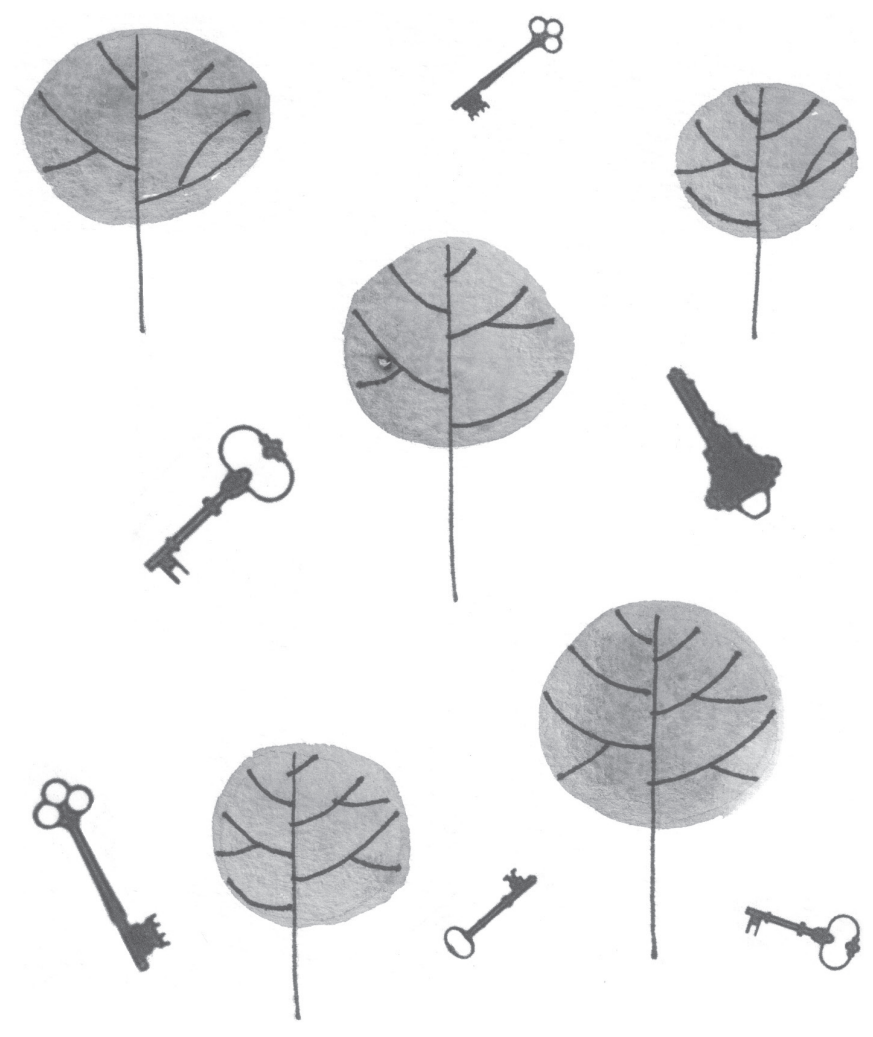

16 Entrevista con Constanza Camelo Suárez, 2011.

17 Entrevista con Constanza Camelo Suárez, 2011. a un punto en el que se transformen en sistemas que funcionan de manera totalmente automática":

son momentos que hay que observar y mirar porque son momentos de los cuales nos podemos inspirar para mirar qué es lo que sale, cómo se produce lo marginal y como el mismo marginal puede producir cosas muy interesantes en los otros, en los que están viendo el comportamiento. ${ }^{16}$

La acción de la artista tiene entonces como afán generar una reacción: "tu acción funciona si produce una reacción". ${ }^{17}$ En una entrevista que otorgó a Helena Martín Franco, ofrece un ejemplo en que un accidente situacional que emergió de Dilatar o contraer el universo se tradujo simplemente en un diálogo:

Una transeúnte del metro se detuvo ante nuestra acción y no entendía lo que estábamos haciendo. Era una inmigrante de Vietnam. Había vivido algo similar, pero su discapacidad no se encontraba en el ámbito de lo visual, sino del lenguaje. La lengua, la palabra fueron para ella la forma de comunicación más difícil de desarrollar cuando migró [Martín Franco, 2008: s. p.].

Los accidentes situacionales que provoca su acción permiten a la artista crear una comunidad de acción efímera que se basa en la comunicación con el otro, sólo si éste acepta cruzar la frontera disonante.

\section{Conclusiones}

La frontera disonante constituye el espacio que propicia la emergencia de estos accidentes situacionales. Ésta es a la vez propia y ajena. Su campo de posibilidades resulta tan amplio como las voluntades de los actores en presencia. No es impuesta por un actor hegemónico, sino que es la raya que el sujeto pinta entre sí mismo y el otro. Ambos son responsables de decidir si la cruzan. "Cada quien la lleva por dentro" de forma permanente, y se constituye a la vez como un mecanismo de defensa y como un punto de encuentro. Cruzarla genera angustia, vértigo y disonancia cognitiva, pero es un paso necesario para que surja una oportunidad de aprendizaje.

Uno puede optar por construir lo que Walter Lippmann llama un pseudoentorno o entorno ficticio, un mundo estereotipado que se interponga entre el sujeto y su alteridad para protegerlo de la disonancia cognitiva. En este caso, acude a su cultura, por 
ejemplo, a los símbolos nacionales proyectados en el Canada Day. Éstos se incrustan en su inconsciente para constituirse como garantía de su identidad. Se erigen entonces como una frontera estereotipada, fija, inmóvil y difícil de desarmar. También, se convierten en un obstáculo para el aprendizaje y la construcción de conocimiento.

La propuesta de Constanza Camelo Suárez nos puede inspirar métodos para desarmar la frontera estereotipada y usar el arte para concebir a la frontera disonante como un espacio lúdico y así reducir la sensación de disonancia cognitiva al momento de cruzarla.

Para ello, plantea repensar nuestras relaciones interpersonales: afirmarse ya no desde el orgullo de residir o haber nacido en algún lugar por casualidad, sino desde el hecho de que todos nos sentimos vulnerables en un momento $u$ otro. Mientras que el gobierno canadiense hace una demostración de fuerza al presumir de la disciplina de su ejército y de su policía para disuadir a cualquiera de cruzar la frontera que lo separa de la multitud, Constanza Camelo Suárez propone decir "ya no tengo fuerza", por lo cual sus actores aparecen invidentes y sordos, ayudados por perros guías, como una manera de "no medir fuerzas" y decir "venga y yo le ayudo, después me ayuda". ${ }^{18}$

En este sentido, los perros son el símbolo de lo que podemos llegar a necesitar $u$ ofrecer, una ayuda mutua. Es el otro que nos puede guiar, mientras nos enceguece la frontera estereotipada, y ayudarnos a recorrer un mundo disonante. Al encontrarse con los ojos vendados, los actores están desarmados; el otro no tiene nada que temer.

En el plano de las relaciones interpersonales e interculturales, lo anterior podría servir para buscar métodos con los cuales combatir, por ejemplo, la xenofobia, cuyas manifestaciones se han multiplicado en la provincia de Quebec este año. En este sentido, la obra y el testimonio de Constanza Camelo Suárez parecen demostrar que expresar una situación de vulnerabilidad en vez de ocultarla detrás de una presunción de fuerza, quizá pueda constituir una actitud propicia para construir empatía.

Finalmente, el encuentro entre la frontera estereotipada que crea el discurso del multiculturalismo canadiense y la frontera disonante sobre la que camina el arte de Constanza Camelo Suárez podría sintetizarse en las siguientes palabras suyas:

No negar que hay una realidad que es más fuerte que nosotros -que es esa realidad mediatizada, esa realidad de la publicidad que vende una imagen y que da un rol al migrante-, pero, al mismo tiempo, venir a presentar el otro lado de lo que puede ser un migrante, que sí es capaz de tener un capital simbólico y producir, a partir de éste, imágenes que lo llevan a existir en el espacio, a ocuparlo, entonces, a ser. ${ }^{19}$

\section{Fuentes}

Andersen, Margaret L.

2006 "Race, Gender, and Class Stereotypes: New Perspectives on Ideology and Inequality", en Norteamérica, RevistaAcadémica del CISAN-UNAM, año 1 , núm. 1, enero-junio, pp. 69-91.

ARdila, RubÉN

1979 Psicología del aprendizaje, Siglo xxi Editores, México, 236 pp.

Augé, Marc

1998 Hacia una antropología de los mundos contem-

Augé, Marc poráneos, Gedisa, Barcelona, 165 pp.

2007 Por una antropología de la movilidad, Gedisa, Barcelona, 165 pp.

Austin, John L.

1962 How to Do Things with Words, Oxford University Press, Londres, 168 pp.

BAILlARgEON, NORMAND

2006 Petit cours d'autodéfense intellectuelle, Lux Éditeur, Montreal, 344 pp.

Beaudoin Duguette, Alexandre

2015 "Propaganda migratoria canadiense y arte latinoamericano en Montreal: un contrapunteo disonante", tesis de doctorado, Universidad Nacional Autónoma de México, México, $294 \mathrm{pp}$.

Beaudoin Duguette, Alexandre

2016 "Propaganda, ventaja competitiva y seguridad nacional: elementos para una contextualización crítica del multiculturalismo canadiense", en Norteamérica. Revista Académica del CISAN-UNAM, año 11, núm. 2, julio-diciembre, pp. 85-105, DOI: $10.20999 /$ nam.2016.b004.

Bernays, EdWARD L.

1961 Crystallizing Public Opinion, Liveright Publishing Corporation, Nueva York, 219 pp.

BERnAYs, EDWARD L.

2008 Propaganda, Melusina, Barcelona, 196 pp.

BHABHA, HOMI K.

2002 El lugar de la cultura, Ediciones Manantial, Buenos Aires, 308 pp.

Bissoondath, NeIL

1994 Selling Illusions: The Cult of Multiculturalism in Canada, Penguin Books, Toronto, 246 pp.

Bouchard, GÉrard

2011 "Qu'est-ce que l'interculturalisme?", en McGill Law Journal / Revue de droit de McGill, vol. 56, núm. 2, pp. 395-468, DOI: 10.7202/1002371ar.

Butler, Judith y Gayatri Chakravorty Spivak

2009 ¿Quién le canta al Estado-nación? Lenguaje, política, pertenencia, Paidós, Buenos Aires, $145 \mathrm{pp}$.

\footnotetext{
${ }^{18}$ Entrevista con Constanza Camelo Suárez, 2011.

${ }^{19}$ Entrevista con Constanza Camelo Suárez, 2011.
} 
Camelo Suárez, Constanza

2008 "Dilater ou contracter l'univers", en Dossier visuel <http://constanzacamelosuarez. com/dossier-visuel/dilater-ou-contracterlunivers / > [15 de marzo de 2017].

Camelo Suárez, Constanza

2015 Constanza Camelo Suárez-Dilaterou contracter l'univers, conferencia en la Universidad Laval, Quebec <https: / / vimeo.com/141461458> [6 de noviembre de 2017]. CHOMsKy, NoAm

2002 "El control de los medios de comunicación", en Noam Chomsky e Ignacio Ramonet, Cómo nos

CHOMsKy, NoAm venden la moto, Icaria, Barcelona, pp. 6-31.

2012 "El objetivo de la educación: La deseducación”, en Rebelión, 29 de marzo <http: / / www. rebelion.org/noticia.php?id=147147> [7 de noviembre de 2017].

Citoyenneté et Immigration CANAdA

2011 "Maria Aragon une jeune Canadienne de 10 ans qui fait sensation sur YouTube", en Histoires de réussite <http:/ /www.cic.gc.ca/francais / ministere/media/histoires/> [17 de abril de 2013].

Crozier, Michel, Samuel P. Huntington

Y JOJI WATANUKI

1975 The Crisis of Democracy. Report on the Governability of Democracies to the Trilateral Commission, New York University Press, Nueva York, $221 \mathrm{pp}$.

Curtis, Adam

2002 The Century of the Self, вBC, Londres (documental).

DaMatta, Roberto

1997 "Carnavales, desfiles y procesiones", en Carnavales, malandros y héroes. Hacia una sociología del dilema brasileño, Fondo de Cultura Económica, México, pp. 55-95.

De Carlo, Maddalena

1997 "Stéréotypes et identité", en Études de Linguistique Appliquée, núm. 107, pp. 279-290.

Ewen, Elizabeth

\section{y StUART Ewen}

2006 Typecasting: On the Arts \& Sciences of Human Inequality, Seven Stories Press, Nueva York,

Festinger, LeON $555 \mathrm{pp}$.

1962 “Cognitive Dissonance”, en Scientific American,

Freire, PAUlo vol. 207, núm. 4, pp. 93-102.

2005 Pedagogía del oprimido, Siglo xxi Editores, Tie-

Gilbert, LietTe rra Nueva, $247 \mathrm{pp}$.

2007 "Legitimizing Neoliberalism Rather than Equality: Canadian Multiculturalism in the Current Reality of North America", en Norteamérica.
Revista Académica del CISAN-UNAM, año 2, núm. 3, enero-junio, pp. 11-36.

Giner, Salvador

1982 Historia del pensamiento social, Ariel, Barcelona, $690 \mathrm{pp}$.

Glick Schiller, Nina y Noel B. Salazar

2013 "Regimes of Mobility Across the Globe", en Journal of Ethnic and Migration Studies, vol. 39, núm. 2, pp. 183-200 <http://dx.doi.org/ $10.1080 / 1369183 X .2013 .723253>$.

Goffman, ERVING

1966 Behavior in Public Places. Notes on the Social Organization of Gatherings, The Free Press, Nueva York, $258 \mathrm{pp}$.

Gómez Peña, Guillermo

2005 Ethno-Techno: Writings on Performance, Activism

Graeber, DAVID and Pedagogy, Routledge, Nueva York, $311 \mathrm{pp}$.

2015 Fragmentos de una antropología anarquista y otros textos, Ediciones La Social, México, 248 pp.

HABERMAS, JÜRGEN

1997 Historia y crítica de la opinión pública, Gustavo Gili, México, 352 pp.

Hegel, Georg Wilhelm Friedrich

2010 Fenomenología del espíritu, Abada, Madrid, $1006 \mathrm{pp}$.

Koestler, Arthur

1964 The Act of Creation, Hutchinson \& Co., Londres, $752 \mathrm{pp}$.

LAFERRIÈRE, DANY

2015 Tout ce qu'on ne te dira pas, Mongo, Mémoire d'encrier, Montreal, 320 pp.

Lévi-Strauss, Claude

1984 Tristes Tropiques, Librairie Plon, París, 512 pp.

LIPPMANN, WALTER

2003 La opinión pública, Cuadernos de Langre, Madrid, $333 \mathrm{pp}$.

Lowenhaupt Tsing, Anna

2005 Friction: An Ethnography of Global Connection, Princeton University Press, Princeton, $321 \mathrm{pp}$.

Marcuse, Herbert

1993 El hombre unidimensional, Planeta, Buenos Aires, $286 \mathrm{pp}$.

Martín Franco, Helena

2008 "Dilater ou contracter l'univers, une entrevue d'Helena Martín Franco avec Constanza Camelo", en .dpi, núm. 12, 16 de junio <http:// constanzacamelosuarez.com/dossiers-presse/ dc-lunivers-helena-martin/ > [ 15 de marzo de 2017].

URRY, JOHN

2007 Mobilities, Polity, Cambridge, 335 pp.

Zarate, Geneviève

1986 Enseigner une culture étrangère, Hachette, París, 160 pp. 